\title{
"Cambio de armas" de Luisa Valenzuela a la luz del pensamiento de Hélène Cixous y de los estudios del trauma
}

\author{
"Other Weapons" by Luisa Valenzuela at the \\ light of Hélène Cixous's thought and trauma \\ studies
}

\section{IOANA GRUIA}

Lingüística General y Teoría de la Literatura

Universidad de Granada

Facultad de Filosofía y Letras

Campus de Cartuja s/n. Granada, 18071

ioanagru@ugr.es

Orcid ID 0000-0003-2098-2243

Resumen: El artículo examina el cuento "Cambio de armas" de Luisa Valenzuela desde una doble perspectiva, comparándolo tanto con las reflexiones de Hélène Cixous sobre la "escritura femenina", la cicatriz y el "pensar la piel”, como con la aportación de los estudios del trauma. La metodología consiste en un análisis minucioso del texto desde este doble enfoque, explicando algunas nociones fundamentales de Cixous y de los estudios del trauma y mostrando su pertenencia a la hora de arrojar luz sobre el sentido del cuento. Las conclusiones pretenden que "Cambio de armas" es un ejemplo privilegiado para una lectura desde este cruce de perspectivas.

Palabras clave: Valenzuela. Cixous. Escritura femenina. Trauma. Cicatriz.
RECIBIDO: 13 DE ABRIL DE 2016 ACEPTADO: 11 DE MAYO DE 2016
Abstract: This paper focuses on the short story "Other weapons" by Luisa Valenzuela from a double perspective, comparing the text both with Hélène Cixous's reflections on "feminine writing", the scar and the "thinking of skin" and with the contribution of trauma studies. The methodology consists in a detailed analysis of the text from this double angle, explaining some fundamental notions of Cixous and of trauma studies and showing its pertinence regarding the construction of the sense of the short story. The conclusions aim to prove that "Other weapons" is a priviledged exemple for a reading from this cross of perspectives.

Keywords: Valenzuela. Cixous. Feminine writing. Trauma. Scar. 


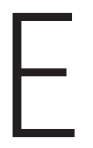

n la amplia y prestigiosa obra literaria de Luisa Valenzuela destacan como elementos fundamentales y estrechamente interrelacionados el cuerpo, las relaciones de poder con una marcada dimensión de género, la meditación sobre el lenguaje y la represión política. El presente artículo propone una interpretación del cuento "Cambio de armas" de la autora argentina desde un doble enfoque: a través de un análisis comparado con las reflexiones de Hélène Cixous sobre la "escritura femenina", la cicatriz y el "pensar la piel", y a la luz de la aportación hecha por los estudios del trauma. El trabajo se propone a la vez considerar el cuento un ejemplo paradigmático del "escribir con el cuerpo" defendido por Valenzuela y Cixous y examinar la marca decisiva de este cuerpo, la cicatriz, a través de su vínculo traumático con la memoria, el lenguaje, la historia personal y colectiva y, por supuesto, con la propia piel. En este sentido, intervienen las reflexiones de la escritora francesa sobre la cicatriz y el potencial político del cuerpo y la piel. "Sostengo que se escribe con el cuerpo, que todo el ser está implicado en el acto de escritura", afirma Valenzuela (2003, 39). Como subraya Markovic, para la autora argentina "escribir con el cuerpo se define [...] como un concepto ético y político" (94). La hipótesis del artículo es que las reflexiones de Cixous con respecto a las nociones de "escritura femenina", "cicatriz" y "pensar la piel" engarzan con el enfoque de los trauma studies y "Cambio de armas" sería un ejemplo privilegiado para una lectura desde este cruce de perspectivas.

Escrito en 1978 (Díaz 1996, 48), el cuento ha suscitado numerosos estudios críticos. El texto pertenece al volúmen homónimo publicado en 1982, que introduce la tortura y el cuerpo torturado como núcleos básicos de narración. Practicada de manera sistemática por la dictadura militar argentina, la tortura deja huellas físicas y psíquicas atroces y desestabiliza el proceso de la memoria. La compleja dialéctica memoria/ olvido y su inscripción no solo en el propio cuerpo, sino también en la relación del yo con su cuerpo y con la historia personal y colectiva, es uno de los hilos conductores de "Cambio de armas". En este sentido es muy pertinente la distinción entre memoria narrativa y memoria traumática formulada por el psicólogo francés Pierre Janet, contemporáneo de Freud, y convertida en una de las bases teóricas -junto con las aportaciones de Freud en Más allá del principio del placer y Moisés y la religión monoteísta- de los estudios del trauma. La articulación memoria/ cuerpo/lenguaje, que vertebra el texto de Valenzuela, es inseparable de las relaciones de poder, subrayadas por la autora como la clave del texto (Mull/ Angulo 351), relaciones que manifiestan al mismo tiempo un componente 
político y de género. La importancia determinante que en el cuento tiene el cuerpo femenino, lugar de inscripción de la historia y a la vez lugar inscrito en el lenguaje y la escritura, es susceptible de vincularse a las reflexiones de Hélène Cixous, principalmente las expuestas en el célebre ensayo de 1975 "La risa de la Medusa".

Ahora bien, hay que subrayar que Valenzuela $(2001,50)$ reivindica más la huella de Kristeva y sus ideas sobre lo abyecto que la impronta de Cixous e Irigaray (Valenzuela 2001, 46), con lo cual se hace difícil hablar de una influencia reconocida o directa con respecto a la autora de La Venue à l'écriture. Medeiros-Lichem (205) afirma explícitamente que "escribir con el cuerpo" no significa lo mismo para Valenzuela que para Cixous en "La risa de la Medusa". No obstante, la voluntad de "escribir con el cuerpo" (Valenzuela 1993, 35-40) manifiesta a mi entender una similitud con las reflexiones de la pensadora francesa, y varios de los argumentos desarrollados en torno al "escribir con el cuerpo" y al "lenguaje femenino" (Valenzuela 2001, 26) pueden compararse con los que Cixous ofrece en "La risa de la Medusa". La crítica al patriarcado de la autora argentina, que denuncia la asimilación entre mujer y "tierra incógnita" (Valenzuela 2001, 44), presenta paralelismos con el texto de Cixous, que subvierte la fórmula freudiana de la sexualidad femenina como "continente negro" (Cixous 2010, 41), poniendo de manifiesto la asociación patriarcal entre mujer y lo desconocido, lo impenetrable, lo peligroso: "Parce que tu es Afrique, tu es noire. Ton continent est noir. Le noir est dangereux. [...] Le «Continent noir» n'est ni noir ni inexplorable. Il n'est encore inexploré que parce qu'on nous a fait croire qu'il était trop noir pour être explorable" (Cixous 2010: 41, 54). En "Análisis profano" (1926) Freud afirma: "De la vida sexual de la niña sabemos menos que de la del niño. Pero no tenemos por qué avergonzarnos de esta diferencia, pues también la vida sexual de la mujer adulta continúa siendo un dark continent para la Psicología" (2001b, 2928). "La dialéctica entre dominadores y dominados" (Mull/Angulo 351), señalada por la autora como rasgo fundamental de "Cambio de armas", aparece asimismo en "Salidas" (ampliación de "La risa de la Medusa"); las reflexiones acerca de la fórmula hegeliana del texto de Cixous pueden aplicarse perfectamente a la violencia ejercida por Roque sobre Laura en "Cambio de armas": "Et l'on sait l'ironie impliquée dans la dialectique du maître et de l'esclave: il ne faut pas que le corps de l'étrange disparaisse, mais il faut que sa force soit domptée, qu'elle revienne au maître" (Cixous 2010, 85). El antiguo torturador de Laura es ahora su marido, controla su cuerpo y su memoria a través 
de medicamentos, la mantiene encerrada en casa bajo la vigilancia de Martina y la sigue sometiendo a vejaciones sexuales y verbales. ${ }^{1}$ También es posible establecer una relación entre "Cambio de armas" y propuestas posteriores de Cixous, como la desarrollada en torno a la cicatriz en Manhattan: Lettres de la prébistoire (2002) y el "pensar la piel" en Hyperrêve (2006), aunque no sea pertinente por supuesto hablar de una influencia directa.

Para Markovic, las ideas de la autora argentina "sobre el lenguaje y el deseo no pueden entenderse fuera del marco del pensamiento feminista francés sobre el mismo tema" (93). La crítica ha señalado en varias ocasiones la impronta del feminismo francés en la obra de Valenzuela y, concretamente, en "Cambio de armas". Medeiros-Lichem, que menciona en la escritora argentina ecos de las reflexiones de Irigaray con respecto a un modelo diferente de enunciación (208), subraya en el cuento que nos ocupa el vínculo con las teorías de Julia Kristeva sobre lo abyecto (217-22). Muñoz (1991, 129; 19941995, 184-85) apunta las huellas de Irigaray y Cixous por lo que respecta al lenguaje femenino originado en el cuerpo. Magnarelli (58-61) señala las diferencias que en su opinión existirían entre el enfoque de la autora argentina y el del feminismo francés. Passalacqua analiza desde la perspectiva de los trauma studies y sobre todo del estudio The Body in Pain (1987) de Scarry el libro de cuentos de la escritora argentina.

Valenzuela define el texto como "un cuento contaminante, un saber al borde del abismo" $(2001,206)$, con efectos en la propia corporalidad y tal vez en los demás, ya que la autora no se atrevió durante un tiempo a enseñarlo, por miedo a poner en peligro a personas cercanas. El cuento está dividido en dieciséis secciones y comienza por "Las palabras", indicando así la importancia decisiva del lenguaje. El fraccionamiento tiene un papel muy destacado, igual que el uso del presente como tiempo narrativo, ya que la fragmentación del texto corresponde a una fractura psíquica (y, como sabremos después, física): la protagonista, desprovista de recuerdos, solo puede vivir en "el presente absoluto" (Valenzuela 2008, 159) y reprime la memoria, representada como un "pozo negro" $(2008,165)$, al fondo del inconsciente (Díaz 1995, 752). La propia Valenzuela, al apuntar el "aliento más largo pero entrecortado, jadeante" $(2001,206)$ del texto, señala la fractura como núcleo conceptual y técnica narrativa. Desde la primera frase sabemos que la memoria es un elemento fundamental, cuya ausencia sorprende al lector, pero en apariencia no al per-

1. Geisdorfer Feal aplica al comportamiento de Roque el término de "wargasm" (162). 
sonaje: "No le asombra para nada el hecho de estar sin memoria, de sentirse totalmente desnuda de recuerdos" (Valenzuela 2008, 157). ${ }^{2}$ La memoria y su opuesto, el olvido, un olvido sospechoso, inquietante, se convierten en ejes centrales del texto. Además, el adjetivo "desnuda" es clave, ya que remite de manera sutil pero clara al cuerpo: "desnuda de recuerdos" quiere decir que los recuerdos estaban allí pero han sido arrebatados. La mente está desnuda igual que un cuerpo podría estar desnudo. Intuimos que un cambio brutal se ha producido; el incipit sitúa así de manera magistral los elementos básicos del cuento: el lenguaje, la memoria narrativa, la memoria traumática, el cuerpo, la historia personal y la historia colectiva. La mente de Laura ha sido convertida -de manera muy violenta, como sabremos a lo largo del texto- en un erial: "Quizá ni siquiera se dé cuenta de que vive en cero absoluto" (Valenzuela 2008, 157). Como explica Brison (41), el trauma implica una profunda perturbación de la memoria, un corte entre el pasado y el presente y una incapacidad de imaginarse el futuro.

Inmediatamente después el texto vuelve a confirmar que la reflexión sobre el lenguaje es un elemento estructurador de "Cambio de armas": "Lo que sí la tiene bastante preocupada es lo otro, esa capacidad suya para aplicarle el nombre exacto a cada cosa y recibir una taza de té cuando dice quiero (y ese quiero también la desconcierta, ese acto de voluntad), cuando dice quiero una taza de té" (Valenzuela 2008, 157). La protagonista habita una "nebulosa" en la que su propio nombre le es comunicado por Martina, una de las únicas dos personas con las que interactúa, siendo la otra "el sinnombre”. Están además "los objetos cotidianos: esos llamados plato, baño, libro, cama, taza, mesa, puerta" (157). Y después, más allá de los límites de la casa -que funciona como una prisión, ya que Laura no puede salir y la función de Martina es no solo asistirla, también (y sobre todo) vigilarla-, está "la fascinación de un otro lado que ella no se decide a enfrentar" (157) a pesar de la aparente ausencia de prohibición.

La primera página concentra una red densa y muy significativa de elementos vinculados, atravesada por la dimensión de género. La memoria no puede disociarse del cuerpo, del lenguaje, de la historia íntima y colectiva. Es justamente la visión de la cicatriz en la espalda lo que desencadena en Laura el proceso de recuperación de la memoria y el regreso a la verdadera

2. Brison observa que "the disappearance of the past and the foreshortening of the future are common symptoms among those who have survived trauma" (43). 
significación del lenguaje, inseparable de la historia íntima y social, y eje de las relaciones de poder del cuento, que tienen un fuerte componente de género: el "sinnombre", el torturador convertido en marido, es a la vez el opresor político y patriarcal. Este doble carácter de la represión militar argentina (Portela 25-27) se enmarca dentro del paralelismo, señalado por corrientes contemporáneas de los estudios de género, entre distintas formas de violencia dentro de una comunidad o nación y la violencia del patriarcado hacia las mujeres (Ivekovic; Yuval-Davis; Yuval Davis/Anthias). Diversas especialistas (Taylor 152; Franco 107; Markovic 205-09) subrayan la feminización que la dictadura militar de Videla practicó sobre los "subversivos" perseguidos y torturados independientemente del sexo y Portela define el contexto argentino de la "Guerra Sucia" como "male hegemonic state", que ejerce una violencia atroz sobre el cuerpo femenino, "inscribing the power of repression onto the body through torture, imprisonement and, often times, death" (29). En el caso concreto de "Cambio de armas", Lagos señala "que los medios que utiliza el coronel para re-entrenar a Laura y transformarla de guerrillera rebelde en un ser pasivo y abúlico coinciden con aquellos utilizados por el sistema patriarcal para reforzar la subordinación de las mujeres" (142). Valenzuela afirma a propósito del cuento: "Para mí fue un texto muy difícil. Ese cuento quería trabajarlo, ampliarlo, pero es tan duro que no lo pude releer nunca más. El arma que se cambia es el sexo, se cambia el arma por el sexo. Es la dominación por el sexo" (en Ordóñez 517).

La cicatriz, marca de inscripción de una infame historia colectiva en el cuerpo, es un elemento determinante en "Cambio de armas", y se encuadra dentro del ámbito semántico de la fragmentación, la fractura y el desgarro, ámbito que atraviesa todo el texto e incluso lo vertebra a nivel estructural a través de la división en dieciséis secciones. Laura descubre su cicatriz al contemplarse en el espejo, ya que la cicatriz está en la espalda, un lugar del cuerpo inaccesible a la mirada directa, que necesita la mediación del espejo. La espalda cobra de esta manera una importancia simbólica fundamental: el acceso de la protagonista a su cicatriz y después a su memoria no es fácil, sino indirecto. La cicatriz se desvela únicamente en el espejo, y tiene una dimensión explícita de extrañeza ("Extraña es como se siente. Extranjera, distinta"), que planea de hecho sobre el cuento entero. Se trata de una extrañeza familiar y cercana a lo "siniestro" (Freud 2001a, 2501), aumentado por el contexto aterrador de la dictadura militar. El cuerpo, la memoria, el lenguaje, las relaciones de poder, todo está bajo el signo de lo "siniestro", de una tenebrosa historia colectiva. El 
acceso a la cicatriz no es directo, como tampoco lo es el acceso a las palabras, a la memoria, al propio nombre y a la historia:

Extraña es como se siente. Extranjera, distinta. ¿¿Distinta de quiénes, de las demás mujeres, de sí misma? [...] esa larga, inexplicable cicatriz que le cruza la espalda y que sólo alcanza a ver en el espejo. Una cicatriz espesa, muy notable al tacto, como fresca aunque ya esté bien cerrada y no le duela. ¿Cómo habrá llegado este costurón a esa espalda que parece haber sufrido tanto? Una espalda azotada. Y la palabra azotada, que tan lindo suena si no se la analiza, le da piel de gallina. Queda así pensando en el secreto poder de las palabras [...]. (Valenzuela 2008, 160-61)

Si el cuerpo, en palabras de Foucault, ${ }^{3}$ se encuentra "directamente inmerso en un campo político" (1994, 32) y constituye la "superficie de inscripción de los acontecimientos" (2000, 32), lo que se escribe/ inscribe en la piel de Laura es una atroz historia colectiva y personal. El recuerdo de la máquina que graba la condena sobre la piel en "La colonia penitenciaria" de Kafka viene enseguida a la memoria. Magnarelli distingue entre dos formas de "escribir con el cuerpo" en la obra de Valenzuela, una positiva y una negativa: "Los personajes no sólo escriben (y se escriben) con el cuerpo, sino que se escriben metafóricamente en sus cuerpos; sus cuerpos son inscritos, marcados, con los signos 'gráficos' de la violencia y la agresión" (56). Refiriéndose específicamente a "Cambio de armas", la estudiosa afirma que "sin duda, el Coronel [...] ha re-escrito a Laura; no sólo le ha dejado marcada la espalda (una cicatriz que él la fuerza a mirar con frecuencia, para que vea la inscripción del poder del amo), sino que además ha borrado su pasado e incluso su lenguaje, imponiéndole el suyo" (57). En la misma línea, Francisca Noguerol analiza la "escritura del cuerpo" de Valenzuela desde "los dos niveles semánticos de la expresión [...]: la dominación que lleva a forzar y a fragmentar la anatomía humana; y [...] las diferentes respuestas ofrecidas por las víctimas ante la violencia, con las que subrayan su fuerza en el nivel somático" (223-24).

La cicatriz de Laura convoca los focos de irradiación que estructuran el texto. En este sentido, conviene retomar las reflexiones de Cixous y los trauma studies desde una perspectiva comparada con "Cambio de armas". "La risa

3. Cuyo libro Vigilar y castigar fue muy leído en la Argentina de la dictadura (Caimari 15-16; Canavese; Markovic 210). 
de la Medusa" comienza enunciando la "écriture féminine", que Cixous no define en ningún momento, siguiendo los presupuestos de la deconstrucción y la voluntad de no teorizar una noción que sitúa bajo el signo del exceso, del desbordamiento, del cuerpo entendido como productor de cultura. La "escritura femenina" remitiría tanto a una inscripción del cuerpo y de la feminidad en el texto como a la necesidad de la mujer de reapropiarse plenamente de su cuerpo, condición indispensable para llegar a la escritura (2010, 37). El imaginario femenino es descrito como un "monde de recherche, d'élaboration d'un savoir, à partir d'une expérimentation systématique des fonctionnements du corps" $(2010,38)$. Cixous defiende la existencia de una escritura marcada $(2010,43)$, que será siempre subversiva $(2010,59)$ y desestabilizadora con respecto al código patriarcal. Hablando del "gynocide" $(2010,59)$ y del "coup de l'Apartheid" ejercido sobre las mujeres (2010, 41), la autora anticipa además el paralelismo que los estudios de género han venido señalando después entre la violencia patriarcal y otros tipos de violencia (ver Regard 13): racista, colonial, de clase o practicada dentro de una nación sobre una comunidad o, en el caso ilustrado por "Cambio de armas", sobre personas consideradas "subversivas".

Es muy importante subrayar que para Cixous el cuerpo no pertenece únicamente a la esfera de la "naturaleza", también -y sobre todo-, a la de la "cultura", entre las que no se plantea una oposición. En este sentido los postulados de Valenzuela se acercan bastante a las reflexiones de la escritora francesa:

Cuando hablo de escribir con el cuerpo me refiero a un trabajo conjunto de la cabeza y lo otro, aquello que nos impulsa a movernos, a bailar, a respirar y exhalar, es decir por lo tanto acarrea a la cabeza y con ella al raciocinio a explorar caminos impensables que suelen asustarnos. (Valenzuela, en Díaz 1996, 29)

Tanto la exploración del lenguaje llevada a cabo por la narradora en "Cambio de armas" como la relación de Laura con las palabras ilustran la idea de la escritora argentina de que "el lenguaje antes de expresarse pasa por zonas preconscientes donde se tiñe de los colores propios del género" (Valenzuela, en Díaz 1996, 28). Y precisa todavía más: "Me refiero a una escritura sin censura, donde la censura interior, freudiana, se anula por completo" (41). Medeiros-Lichem afirma (85) que la elaboración de un "lenguaje femenino" 
en la escritura de Luisa Valenzuela se consigue a través de la superación del paradigma patriarcal, que excluye la mirada femenina. Es precisamente lo que Cixous, que denuncia que "la femme a toujors fonctionné «dans» le discours de l'homme" (2010, 57), defiende en "La risa de la Medusa" a través de la figura de la "voleuse" $(2010,62)$, jugando con la ambivalencia del verbo "voler", que en francés significa tanto 'volar' como 'robar'. Valenzuela sostiene "la existencia de un lenguaje femenino aunque éste no haya sido aún del todo desvelado y aunque la frontera con el otro -el lenguaje cotidiano con impronta de hombre- sea demasiado sutil y ambigua como para ser trazada" (2001, 26). La relación de Laura con el lenguaje se sitúa desde el principio del cuento bajo el signo de la sospecha y de la desnaturalización: "esos llamados plato, baño, libro, cama, taza, mesa, puerta". El lenguaje verdadero, que la protagonista debe reconquistar al igual que debe reconquistar su memoria, pertenece al "otro lado", a "la fascinación de un otro lado", que marca a comienzos del texto la oposición a "este lado" (Valenzuela 2008, 157), donde Laura vive prisionera de Roque y de Martina. En su análisis de "Cambio de armas", Passalacqua cita varias veces a Scarry, que observa las etapas del vínculo entre dolor físico, ausencia del lenguaje y recuperación de este: "Physical pain is not only itself resistant to language, but also actively destroys language [...]. Conversely, to be present when the person in pain rediscovers speech and so regains his powers of self-objetivation is almost to be present at the birth, or rebirth, of language" (Scarry 172). Acceder de nuevo al lenguaje y a la memoria narrativa es algo que Laura logra completamente solo al final de "Cambio de armas" y a través del cuerpo, cuyo potencial liberador está también al "otro lado": se trata no ya del cuerpo utilizado de manera violenta por el hombre, sino del cuerpo en un sentido cixousiano, que aúna naturaleza y cultura y permite acceder a la verdad, una verdad terrible y traumática, de la historia íntima y colectiva. En una magistral distribución tanto de la tensión narrativa como de la progresiva elaboración de los varios elementos fundamentales interrelacionados, el cuerpo se muestra de manera gradual como inseparable de la memoria, como desencandenante de esta, y como indisoluble a la vez del lenguaje, puesto que las palabras son visualizadas a través del cuerpo:

La llamada angustia es otra cosa: la llamada angustia le oprime a veces la boca del estómago y le da ganas de gritar a bocca chiusa, como si estuviera gimiendo. Dice -o piensa- gimiendo, y es como si viera la imagen de la palabra, una imagen nítida a pesar de lo poco nítida que puede ser una 
simple palabra. Una imagen que sin duda está cargada de recuerdos (¿y dónde se habrán metido los recuerdos? ¿Por qué sitio andarán sabiendo mucho más de ella que ella misma?). (Valenzuela 2008, 158)

Si Laura puede ver la imagen de la angustia y el gemido es porque el recuerdo de estos está instalado en su cuerpo y la imagen a su vez despierta los recuerdos solo accesibles, como veremos, mediante la memoria del cuerpo, la cicatriz. La elección de las palabras muestra esta imbricación de campos semánticos, porque cuerpo, memoria, lenguaje y mente se construyen como inseparables: para recuperar un recuerdo hay que tender una "mano mental" y la memoria se agazapa en el cuerpo igual que un animal o un ser humano perseguido, aterrado, sin acceso a las palabras debido al terror:

Algo se le esconde, y ella a veces trata de estirar una mano mental para atrapar un recuerdo al vuelo, cosa imposible; imposible tener acceso a ese rincón de su cerebro donde se le agazapa la memoria. Por eso nada encuentra: bloqueada la memoria, enquistada en sí misma, como en una defensa. (Valenzuela 2008, 158)

La metáfora espacial de la memoria, representada como "pozo negro", es muy significativa, y estrechamente relacionada con el divorcio entre el lenguaje y las cosas, que afecta a la esfera más íntima (que es a la vez, por supuesto, política): “el llamado amor" (Valenzuela 2008, 165), que remite a las palabras y al comportamiento vejatorios del protagonista masculino. Este divorcio pone de relieve la desestabilización de todo un sistema cotidiano de referencias: las palabras ya no significan lo que se espera de ellas y Laura, al preguntarse por el lenguaje y esta discrepancia, realiza un trabajo de recuperación de su propia historia y empieza a ser consciente de la existencia de una "zona oscura de su memoria" (Valenzuela 2008, 165), para preguntarse enseguida qué es la memoria, a qué realidad responde este concepto: “¿memoria?” (Valenzuela 2008, 165).

La memoria, inseparable del cuerpo, se sitúa en el mismo campo semántico del desgarro, la fractura, la cicatriz. Si la cicatriz es el signo epidérmico, exterior, de la tortura, hay también un "desgarramiento interno" (Valenzuela 2008, 164), producido no sólo por las vejaciones sexuales -y de lenguaje- a las que Roque la somete en el presente -“¡Abrí los ojos, puta!” (Valenzuela 2008, 164), le grita este al violarla-, sino también por el recuerdo de otras vejaciones 
pasadas, relacionadas con la condición de Laura de detenida política: "Abrí los ojos, cantá, decime quién te manda, quién dio la orden" (Valenzuela 2008, 164). Estas palabras, que acuden de golpe a la mente de Laura en el mismo momento en que el hombre la agrede sexual y verbalmente, pueden representar el primer estímulo de la memoria traumática, tal como la analiza Pierre Janet (274). A diferencia de la memoria narrativa, capacidad humana de ordenar los acontecimientos del pasado, la memoria traumática sería el estado en el que, si hay un estímulo, los eventos traumáticos son, parcial o completamente, reexperimentados a través de sueños, pesadillas o flashbacks. Brison explica el carácter somático de la memoria traumática (42) y la importancia de transformarla en memoria narrativa a través del lenguaje (40). La autora (41) invoca, recurriendo a las ideas de John Locke expuestas en An Essay Concerning Human Understanding (1694), la perspectiva del yo como una suma de recuerdos continuos, una narrativa. $\mathrm{Al}$ producirse el trauma, esta narrativa se encontraría intensamente desestabilizada, debido a la resistencia del sujeto a recordar el evento traumático y a la parálisis que dicho evento, que tarda en ser asimilado de manera racional pero que tiene efectos devastadores a nivel somático, provoca a la hora de proyectar un futuro. La memoria traumática, explica Brison, ${ }^{4}$ está vinculada al cuerpo, borra la distinción cartesiana entre este y la mente y se manifiesta a través de sensaciones corporales de profunda ansiedad, parálisis, llanto descontrolado o terror. Carece del carácter narrativo que solo el lenguaje puede darle, al articularla precisamente como memoria narrativa, capaz de ordenar y dar forma a los acontecimientos atroces y de intentar recuperar el sentimiento de un yo cohesionado, que asimila el pasado e imagina el futuro.

El tránsito de la memoria traumática a la memoria narrativa es especialmente difícil en el caso de Laura, debido tanto a que la magnitud del trauma ha debilitado el vínculo entre la mujer y el propio lenguaje, como a su resistencia a acordarse de una historia, a la vez íntima y colectiva, atroz. Corporalmente, la protagonista está habitada, invadida, por el recuerdo de la tortura materializado en la cicatriz. Como subraya Caruth, una de las teóricas más reconocidas de los estudios del trauma, "to be traumatized is precisely to be possessed by an image or event" (1995, 4-5), pero también por la resistencia a

4. La estudiosa cuenta en este texto y en otros su propio trauma de enormes proporciones, habiendo sido violada, golpeada salvajemente y abandonada casi al borde de la muerte. A partir de esta experiencia atroz, explica, intentó analizar el funcionamiento de la memoria traumática, de la memoria narrativa y del vínculo con el lenguaje. 
asimilar el trauma, que vuelve bajo forma de pesadillas o flashbacks de manera literal y no simbólica $(1995,5)$. Las palabras del antiguo torturador y actual marido (en una boda fantasmal de la que Laura no recuerda nada) regresan a la memoria de modo literal y tardío, aunque hayan estado siempre allí latentes, ${ }^{5}$ agazapadas en el cuerpo y resistentes al recuerdo, representando en cierto sentido lo que Freud llamó en Moisés y la religión monoteísta "el retorno parcial de lo reprimido" $(1986,113)$.

Si las palabras aceleran el proceso de la memoria traumática y su conversión, al final del relato, en memoria narrativa -también en historia, ya que la memoria recupera tanto la historia personal como la colectiva-, el primer estímulo de esta transformación es la mirada a la cicatriz. Recordemos el pensamiento de Laura inmediatamente después de contemplar su cicatriz en el espejo: "Y la palabra azotada, que tan lindo suena si no se la analiza, le da piel de gallina" (Valenzuela 2008, 161). Para examinar la importancia de la cicatriz en el texto, es necesario acudir a las reflexiones que Cixous hace en Manhattan: Lettres de la prébistoire:

La Cicatrice: The Scar. Thème d'une richesse signifiante extraordinaire, à tous les niveaux et sous tous les aspects, tant langagier, [...] tant littéral que métaphorique que psychanalytique: trauma, trace d'une blessure, [...] tant au niveau philosophique trace, greffe, graphe, marque; qu'au niveau géologique, géographique, géopolitique. [...] Innombrables sont les domaines cicatriciels. $(2002,189)$

La propia literatura se sitúa para Cixous bajo el signo de la cicatriz: "D’ailleurs la Littérature est toute cicatricielle. Elle célèbre la plaie et redit la lésion” (2002, 189). Recordemos que en la Odisea de Homero, Ulises, de vuelta a Ítaca, es reconocido por su nodriza Euriclea precisamente por su cicatriz de la infancia. Ulises, maestro en la invención de múltiples identidades, no puede disimular la huella de una antigua herida que desvela de inmediato su verdadero nombre. Si Cixous habla de los "dominios cicatriciales", podemos decir que el cuerpo de Laura sería un "territorio cicatricial" (Gruia 263), marcado por la herida y por la huella de la herida. La piel se convierte así en superficie de inscripción de la tortura, de una convulsa historia colectiva. Conviene en este sentido recurrir a otra reflexión de Hélène Cixous, que exhorta a "pensar la piel". Así,

5. Freud subraya en Moisés y la religión monoteísta el periodo de latencia del trauma (1986, 91). 
en Hyperrêve escribe: "Politiquement, poétiquement, écologiquement, médicalement, philosophiquement, penser la peau. La peau de la pensée" (2006, 41). Las palabras de Cixous se inscriben en la línea del imaginario literario y filosófico contemporáneo, que presta una gran atención a la piel, la superficie y la vulnerabilidad. ${ }^{6}$ Gilles Deleuze, haciendo referencia a la célebre afirmación de Valéry "Lo más profundo que hay en el hombre es la piel” (40), explica el estatus fundamental de la piel como intersección de lugares físicos y categorías filosóficas (126). La superficie se convierte así, según Deleuze, en el lugar del sentido. Cabe recordar también al respecto la formulación de "Yo piel" de Didier Anzieu y su carácter determinante en la misma posibilidad del pensamiento: "Le Moi-peau fonde la possibilité même de la pensée" (62). Anzieu subraya asimismo que la piel es una superficie de inscripción de las huellas del otro.

En el caso que nos ocupa, la piel de Laura ha sido marcada por la tortura y una herida imborrable en un lugar díficilmente accesible. Una cicatriz en la espalda solo puede verse en el espejo o ser contemplada por otro si la espalda está desnuda. Se refuerza así la unión entre relaciones de poder, relaciones sexuales y represión política. Además, la cicatriz de Laura apunta a un problema fundamental, a nivel de memoria, historia personal e historia colectiva: la relación con la verdad y la oposición entre la terrible verdad inscrita en el cuerpo y la verdad distorsionada del poder represivo: "La verdad nada tiene que ver con él, que sólo dice lo que quiere decir y lo que quiere decir nunca es lo que a ella le interesa. Posiblemente la verdad no sea importante para él" (Valenzuela 2008, 165). La ventana que Laura no puede abrir porque él se ha llevado el picaporte funciona como metáfora perfecta de la verdad truncada: el hombre le impide el acceso a la verdad, igual que le impide asomarse a la ventana. Las dos acciones, además, implicarían "un vértigo difícilmente controlable" (Valenzuela 2008, 164). La comparación del picaporte, la "llave" de la ventana, con un arma, apunta hacia un doble significado: el picaporte es la parte sustraída, importantísima, de la verdad oculta y el picaporte constituye un signo de poder, un arma:

Y de golpe lo imagina a él paseando por las calles con un picaporte ovalado de ventana en el bolsillo, picaporte como un arma para apretar en el puño y pegar la trompada.

6. Por mencionar solo dos contribuciones de las últimas décadas, podemos hacer referencia a Butler y sus reflexiones sobre los "cuerpos que importan" y las "vidas precarias" y a Cavarero, que propone el término de "horrorismo" para nombrar la violencia contemporánea. 
¿Arma, calle, puño? por qué se le ocurrirán esas ideas. La noción de calle no es en realidad lo que más la perturba. La noción de arma, en cambio... (Valenzuela 2008, 165)

La ventana imposible de abrir es la metáfora de una historia incompleta, cuyo acceso a la verdad es obstruido, una historia carente de la parte más significativa -y terrible- de la verdad. En lugar de revelar, la ventana "desrevela", oculta, funciona solo como encuadre de una visión limitada y no como posibilidad de descubrimiento: "Esta ventana aquí, tan desreveladora, ventana que en lugar de abrir un panorama lo limita" (Valenzuela 2008, 165). De la misma manera, la información suministrada por el hombre y por la historia oficial (sabemos que el protagonista es un alto mando militar de la dictadura) es sumamente filtrada y distorsionada. Cobra así un significado muy importante la comparación entre la memoria paralizada y la ventana que da a una pared, bloqueando el acceso a la verdad: "El pozo negro de la memoria, quizá como una ventana a una pared blanca con ciertas chorreaduras" (Valenzuela 2008, 165).

El grado más alto de cinismo por lo que respecta a la distorsión de la verdad se alcanza con la visita de los "colegas" del hombre a la casa, que le preguntan a Laura por sus "problemas" de espalda. La cicatriz misma, que da testimonio de la verdad, se ve negada, "olvidada" deliberadamente, transformada en un banal "problema", inscribiéndose en una serie de transformaciones en apariencia apacibles y en realidad violentas: los "problemas" de espalda pertenecen a la misma esfera que el color rosado de la casa, ambos elementos están destinados a borrar la memoria de Laura, a instalarla en un espacio, un tiempo, una historia y un lenguaje anestesiantes y artificiales. A la protagonista se le niega el acceso tanto a la memoria traumática como a la memoria narrativa, ya que se pretende dejarla sin memoria. Únicamente el cuerpo, a través de la cicatriz, es capaz de devolverla a la historia íntima y social (y, por supuesto, al lenguaje). En este sentido se trata de un cuerpo productor de lenguaje y de memoria cultural, como defiende Cixous, y también de un cuerpo situado bajo el signo de la herida y la cicatriz, mutilado (Laura tiene, aparte de la marca que le atraviesa, la nariz rehecha después de haber sido rota por Roque), como el "corps mutilé de Méduse" (Cixous 2010, 23). MorelloFrosch señala que "es por este cuerpo y su elemental memoria de sufrimiento y escarnio que [Laura] puede lograr la penosa reconstrucción de una historia fracturada. Una vez más, el cuerpo deviene locus de saberes que la conciencia ha obturado" (122). La misma estudiosa apunta también la dependencia en- 
tre la historia personal suprimida y la historia colectiva distorsionada (122). Cordones-Cook (58) y Hatry (338) comparan la amnesia de Laura con la amnesia colectiva en Argentina. Valenzuela menciona al respecto el deseo de no saber, manifestado en los primeros años de la dictadura: "En el 79 ya se estaba empezando a cerrar los oídos al horror, ya se había instalado entre la gente una negación casi freudiana. [...] Quizá como posibilidad de supervivencia [el pueblo] ya no quería enterarse, más bien no quería convencerse de que estaba ocurriendo algo tan ominoso" (en Burgos/Fenwick 207).

En este sentido, tal vez se pueda hablar de una historia "desaparecida", igual que de personas "desaparecidas". Caruth señala la existencia de "a bistory of disappearence" en el mundo contemporáneo y se pregunta: "What does it mean for history to disappear?" (2013, x). La memoria de Laura ha sido borrada y, al final del cuento, reconquistada, pero la resistencia de la protagonista a saber de manera consciente, a transformar en lenguaje y narración lo que está escrito en el cuerpo (de algún modo, lo que sabe con el cuerpo) no puede ser ignorada. ${ }^{7}$ La conversión de la memoria traumática en memoria narrativa, que pasa por la cicatriz, la piel y el cuerpo, implica también la tensión entre saber, no saber (porque la verdad ha sido ocultada) y deseo de no saber o resistencia a saber (porque la verdad es demasiado atroz). Analizando las reflexiones de Más allá del principio del placer, donde Freud recurre a la historia de Tancredo y Clorinda de ferusalén liberada de Tasso para explicar la neurosis traumática, Caruth observa: "If Freud turns to literature to describe traumatic experience, it is because literature, like psychoanalysis, is interested in the complex relation between knowing and not knowing" (1996, 3). En el caso de Laura, el no saber se debe tanto al ocultamiento sistemático de la verdad y a los medicamentos que Roque le administra para borrar su memoria, como a la resistencia a saber que presenta la propia protagonista. La cicatriz, la piel, el cuerpo, funcionan como elementos básicos para alcanzar el saber, la memoria narrativa y la historia personal y colectiva. El "cambio de armas" final representa un cierre a la vez rotundo y fecundamente ambiguo: no sabemos si la protagonista dispara o no, pero sí sabemos que ha llegado a recordar y reconstruir, sobre todo a través de su cuerpo, su historia íntima y la historia social y que ha transformado la memoria traumática inicial en una memoria narrativa. Escribir con el cuerpo se convierte pues en una estrategia vital y

7. Freud analiza, en Más allá del principio del placer, la resistencia a recordar sucesos traumáticos (1979, 95-96). 
literaria para reflexionar acerca de un profundo trauma personal y colectivo, hacerlo visible mediante el lenguaje y devolver así a través de la literatura la memoria individual e histórica.

\section{OBRAS CITADAS}

Anzieu, Didier. Le Moi-peau. Paris: Dunod, 1965.

Brison, Susan J. "Trauma Narratives and the Remaking of the Self". Acts of Memory: Cultural Recall in the Present. Eds. Mieke Bal, Jonathan Crewe y Leo Spitzer. Hanover: University Press of New England, 1999. $39-54$.

Burgos, Fernando, y M. J. Fenwick. "Literatura y represión: perspectivas de Luisa Valenzuela”. Entrevista. Arizona fournal of Hispanic Cultural Studies 5 (2001): 203-22.

Butler, Judith. Bodies that Matter: On the Discursive Limits of "Sex". New York: Routledge, 1993.

Butler, Judith. Precarious Life: The Powers of Mourning and Violence. London: Verso, 2004.

Caimari, Lila. "Usos de Foucault en la investigación histórica". Documentos de trabajo de la Escuela de Educación 18 (2005). 27 de agosto de 2015. <http:// live.v1.udesa.edu.ar/files/EscEdu/DT/DT18-CAIMARI.PDF>.

Canavese, Mariana. "El espacio público entre la asfixia y la resistencia: usos de Foucault durante la dictadura argentina". Polis: revista latinoamericana 31 (2012). 27 de agosto de 2015. <http://polis.revues.org/3624>.

Caruth, Cathy, ed. Trauma: Explorations in Memory. Baltimore: Johns Hopkins UP, 1995.

Caruth, Cathy. Unclaimed Experience: Trauma, Narrative and History. Baltimore: Johns Hopkins UP, 1996.

Caruth, Cathy. Literature in the Ashes of History. Baltimore: Johns Hopkins UP, 2013.

Cavarero, Adriana. Orrorismo ovvero della violenza sull'inerme. Milano: Feltrinelli, 2007.

Cixous, Hélène. Manhattan: Lettres de la préhistoire. Paris: Galilée, 2002.

Cixous, Hélène. Hyperrêve. Paris: Galilée, 2006.

Cixous, Hélène. Le Rire de la Méduse et autres ironies. Paris, Galilée, 2010.

Cordones-Cook, Juanamaría. Poética de la transgresión en la novelística de Luisa Valenzuela. New York: Peter Lang, 1991. 
Deleuze, Gilles. Logiques du sens. Paris: Minuit, 1969.

Díaz, Gwendolyn. "Politics of the Body in Luisa Valenzuela's Cambio de armas y Simetrias". World Literature Today 69.4 (1995): 751-56.

Díaz, Gwendolyn. "Entrevista con Luisa Valenzuela". La palabra en vilo: narrativa de Luisa Valenzuela. Eds. Gwendolyn Díaz y María Inés Lagos. Santiago de Chile: Cuarto Propio, 1996. 27-52.

Foucault, Michel. Vigilar y castigar. Trad. Aurelio Garzón del Camino. Madrid: Siglo XXI, 1994.

Foucault, Michel. Nietzsche, la genealogía, la historia. Trad. José Vázquez Pérez. Valencia: Pre-textos, 2000.

Franco, Jean. "Gender, Death and Resistance: Facing the Ethical Vacuum". Fear at the Edge: State Terror and Resistance in Latin America. Berkeley: University of California Press, 1992. 104-18.

Freud, Sigmund. Psicología de las masas. Más allá del principio del placer. El porvenir de una ilusión. Trad. Luis López Ballesteros. Madrid: Alianza, 1979.

Freud, Sigmund. Moisés y la religión monoteista. Trad. Luis López Ballesteros. Madrid: Alianza, 1986.

Freud, Sigmund. "Lo siniestro". Obras completas. Vol. 7. Trad. Luis López Ballesteros. Madrid: Biblioteca Nueva, 2001a. 2483-505.

Freud, Sigmund. "Análisis profano". Obras completas. Vol. 8. Biblioteca Nueva, 2001b. 2911-959.

Geisdorfer Feal, Rosemary. "The Politics of «Wargasm»: Sexuality, Domination and Female Subversion in Luisa Valenzuela's Cambio de armas". Structures of Power. Eds. Terry J. Peavler y Peter Standish. Albany: SUNY Press, 1996. 159-83.

Gruia, Ioana. "Territorios cicatriciales en la narrativa de Juan Marsé: el caso de Rabos de lagartija". Bulletin Hispanique 116.1 (2014): 263-81.

Hatry, Laura. "Género, poder y violencia en la obra de Luisa Valenzuela". Boletín Millares Carlo 29 (2010): 333-48. 20 de agosto de 2015. <http:// mdc.ulpgc.es/cdm/ref/collection/bolmc/id/418>.

Ivekovic, Rada. Le Sexe de la nation. Paris: Léo Scheer, 2003.

Janet, Pierre. Les Médications psychologiques: études historiques, psychologiques et cliniques sur les méthodes de la psychotérapie. Vol. 2. Paris: Société Pierre Janet, 1919.

Lagos, María Inés. "Sujeto, sexualidad y literatura en «Cambio de armas» y Novela negra con argentinos de Luisa Valenzuela". La palabra en vilo: 
narrativa de Luisa Valenzuela. Eds. Gwendolyn Díaz y María Inés Lagos. Santiago de Chile: Cuarto Propio, 1996. 131-61.

Magnarelli, Sharon. "Luisa Valenzuela: cuerpos que escriben (metonímicamente hablando) y la metáfora peligrosa". La palabra en vilo: narrativa de Luisa Valenzuela. Eds. Gwendolyn Díaz y María Inés Lagos. Santiago de Chile: Cuarto Propio, 1996. 53-78.

Markovic, Ana. "La identidad femenina y las relaciones de poder en la obra de Luisa Valenzuela". Tesis doctoral. Universitat de Barcelona, 2009. 16 de agosto de 2015. <http://diposit.ub.edu/dspace/bitstream/2445/44343/1/ MARKOVIC TESIS.pdf $>$.

Medeiros-Lichem, María Teresa. La voz femenina en la narrativa latinoamericana: una relectura crítica. Santiago de Chile: Cuarto Propio, 2006.

Morello-Frosch, Marta. "Relecturas del cuerpo en Cambio de armas de Luisa Valenzuela". La palabra en vilo: narrativa de Luisa Valenzuela. Eds. Gwendolyn Díaz y María Inés Lagos. Santiago de Chile: Cuarto Propio, 1996. 113-30. Mull, Dorothy, y Elsa Angulo. "An afternoon with Luisa Valenzuela". Entrevista. Hispania 69 (1986): 350-52.

Muñoz, Willy O. "Del falogocentrismo a la escritura ginocéntrica: Cambio de armas de Luisa Valenzuela". Antipodas: Fournal of Hispanic Studies of the University of Auckland 3 (1991): 125-34.

Muñoz, Willy O. "El lenguaje hémbrico en «Cambio de armas»". Antípodas: Fournal of Hispanic Studies of the University of Auckland 6-7 (1994-1995): 183-89.

Noguerol, Francisca. "De los cuerpos forzados a la fuerza del cuerpo". En cursiva: Escribir el cuerpo. 19 asedios desde la literatura hispanoamericana. Eds. Carmen de Mora y Alfonso García Morales. Sevilla: Universidad de Sevilla, 2003. 223-37.

Ordóñez, Montserrat. "Máscaras de espejos, un juego especular: entrevistaasociaciones con la escritora argentina Luisa Valenzuela". Revista Iberoamericana 51.132 (1985): 511-19.

Passallacqua, Camille. “The Corporeal Trauma Narratives of Gayl Jones's Corregidora, Phyllis Alesia Perry's Stigmata and Luisa Valenzuela's Cambio de armas". Chapel Hill: University of North Carolina, 2009. 20 de agosto de 2015. <https://cdr.lib.unc.edu/indexablecontent/uuid:3afc60bf9cc2-4e90-97f1-9963acba9e9b>.

Portela, Edurne. Displaced Memories: The Poetics of Trauma in Argentine's Women's Writing. Lewisburg: Bucknell UP, 2009. 
Regard, Frédéric. “AA!”. Hélène Cixous. Le Rire de la Méduse et autres ironies. Paris: Galilée, 2010. 9-22.

Scarry, Elaine. The Body in Pain: The Making and Unmaking of the World. New York: Oxford UP, 1987.

Taylor, Diana. Disappearing Acts: Spectacles of Gender and Nationalism in Argentina's "Dirty War". Durham: Duke UP, 1997.

Valenzuela, Luisa. "Escribir con el cuerpo". Alba de América 11.20-21 (July 1993): 35-40.

Valenzuela, Luisa. Peligrosas palabras. Buenos Aires: Temas Grupo Editorial, 2001.

Valenzuela, Luisa. Escritura y secreto. Madrid: FCE, 2003.

Valenzuela, Luisa. Cuentos completos y uno más. México D.F.: Alfaguara, 2008.

Valéry, Paul. La idea fija. Trad. Carmen Santos. Madrid: Visor. 1988.

Yuval-Davis, Nira. Gender and Nation. London: Sage, 1997.

Yuval-Davis, Nira, y Fiora Anthias, eds. Woman-Nation-State. London: Macmillan, 1989. 